\title{
A colocação dos clíticos em sentenças finitas: um estudo sócio-histórico das vertentes do PB em cartas do sertão baiano (século $\mathrm{XX}$ )
}

\section{Clitics placement in finite sentences: a socio- historical study of the PB's strands in letters from the sertão of Bahia (20th Century)}

\author{
Mariana Fagundes de Oliveira Lacerda* \\ Maiara da Silva Lemos** \\ Zenaide de Oliveira Novais Carneiro***
}

\begin{abstract}
RESUMO
O presente trabalho visa realizar a descrição da colocação dos clíticos pronominais nas orações finitas com verbo único e grupos verbais em amostras representativas das vertentes do PB culto, semiculto e popular, segundo Lucchesi (2015), através de cartas pessoais manuscritas por escreventes de escolaridade diversa da região do sertão baiano que compõem acervos disponibilizados no Corpus Eletrônico de Documentos Históricos do Sertão (CE-DOHS/UEFS) e em Almeida, Carneiro e Oliveira (2011). A pesquisa fundamentada pelos pressupostos teóricos da linguística sócio-histórica (MATTOS E SILVA, 2008), segue as agendas propostas pelo Projeto Para a História do Português Brasileiro (PHPB), conforme Lobo (2009), contribuindo com o campo de estudo das mudanças linguísticas e com o campo
\end{abstract}

Recebido em 22 de maio de 2020.

Aceito em 24 de setembro de 2020.

DOI: http://dx.doi.org/10.18364/rc.2021n61.426

\footnotetext{
*Universidade Estadual de Feira de Santana, marianafag@gmail.com, orcid.org/0000-0003-4335-3458

**Universidade Estadual de Feira de Santana, maiaraslemos@gmail.com, orcid.org/0000-0001-5227-6787

***Universidade Estadual de Feira de Santana, zenaide.novais@gmail.com, orcid.org/0000-0001-5990-4854
}

Confluência. Rio de Janeiro: Liceu Literário Português, n. 61, p. 299-334, jul.-dez. 2021 
de reconstrução da história social linguística. A finalidade, foi verificar se, nos corpora desta pesquisa, pode-se atestar a hipótese levantada por Lucchesi (1994) acerca da tendência à aproximação das vertentes no $\mathrm{PB}$, decorrente dos processos de urbanização e industrialização no século XX. Por fim, a aproximação entre as vertentes culta, semiculta e popular, confirma a hipótese de Lucchesi (1994).

Palavras-chave: Sócio-história. Colocação dos clíticos. Vertentes do PB. Cartas. Sertão baiano.

\section{ABSTRACT}

The present work evidences the placement description of pronominal clitics in the single verb and verbal groups in finite sentences with in representatives trands cultured, semi-cultand popular aspectof BP through personal letters written by scribes of diverse education of the region of the sertão of Bahia that compose some collections available in the Electronic Corpus of History Sertão Documents (CEDOHS/UEFS) and in Almeida, Carneiro and Oliveira (2011). The research founded by the theoretical assumptions of socio-historical linguistics (MATTOS E SILVA, 2008), follows the research agendas proposed by the Project for the History of Brazilian Portuguese (PHPB), according to Lobo (2009), contributing to the field of study of linguistic changes and field that holds the reconstruction of linguistic social history. The purpose of this study was to verify if the corpora of this research, we can attest he hypothesis raised by Lucchesi (1994) about the tendencyto approach strands in the BP, due from the urbanization and industrialization processes in the XX century. Finally, we can see the approximation between the cultic, semi-cult and popular slopes, confirming the hypothesis of Lucchesi (1994) and, it is noted, at some level, the presence of a competition between grammars among scribes with higher education levels, evidencing the importance of the influences exerted by the standardized norm acquired through the schooling processes.

Keywords: Socio-history. Cliticsplacement. BP strands. Letters. Sertão of Bahia.

\section{Introdução}

A colocação dos clíticos é um assunto que atrai bastante a atenção de pesquisadores da área da linguística, devido ao fato de que, "na história do português e na formulação de teorias gramaticais, os clíticos pronominais ocupam lugar de destaque, em função de seu estatuto híbrido." (PAGOTTO; DUARTE, 2005, p. 67). Como aponta Martins (2013), os clíticos são itens lexicais que estão entre a categoria de afixo, já que são fonologicamente 
dependentes de outro elemento, e a de palavra, pois possuem certa independência morfossintática.

Esse fenômeno linguístico revela mudanças ocorridas no português ao longo do tempo, definindo diferentes estruturas que são expressas em contextos específicos nas construções finitas com verbo único e com grupos verbais. Assim, com base na pesquisa de Galves, Britto e Paixão de Souza (2005), os contextos relevantes nas construções com verbo único são: i) sentenças com verbo em posição inicial absoluta e ii) sentenças raízes principais afirmativas com verbo antecedido de sujeito neutro, sintagma preposicional e sintagma adverbial, com advérbios não atratores de próclise. No primeiro contexto, nota-se a ênclise categórica em toda história do português na Europa ao passo que no Português Brasileiro (doravante PB), a colocação pós-verbal ocorre apenas em situações de formalidade. Do mesmo modo, no segundo contexto, o Português Europeu Contemporâneo (doravante PE) é marcado pela colocação enclítica, já o PB se caracteriza pela predominância da próclise.

Em relação às sentenças formadas por grupos verbais, a relevância da colocação dos clíticos é evidenciada pela possibilidade inovadora do PB em permitir a próclise ao verbo infinito, colocação não registrada na história do português na Europa. Além disso, pesquisas como as de Pagotto (1992) e Carneiro (2005) mostram que o PB é marcado pela queda da subida do clítico nas construções não passivas, ou seja, o clítico argumento do verbo regente aparece adjacente ao verbo infinito.

Considerando essas questões, o presente estudo, realizado no âmbito do mestrado acadêmico por Lemos (2019) sob orientação da professora doutora Zenaide Carneiro e com contribuições da professora doutora Mariana, objetivou fazer a descrição da colocação dos clíticos nas orações finitas com verbo único e grupos verbais nos contextos relevantes citados acima, utilizando corpora da linguagem escrita, datados do século XX, composto por um total de 254 documentos, entre cartas e cartões, manuscritos por remetentes de diversos níveis de escolaridade, residentes de localidades do sertão baiano, em que se entende por sertão baiano as cidades do semiárido 
da Bahia, de acordo com a delimitação realizada pela Superintendência do Desenvolvimento do Nordeste (Sudene) em dezembro de 2017. Dessa maneira, fazem parte dos corpora desta pesquisa três acervos de cartas que compõem o Corpus Eletrônico de Documentos Históricos do Sertão (CE-DOHS/UEFS) e as Cartas Brasileiras (1809 - 2000) Coletânea de fontes para o estudo do português, organizada por Almeida, Carneiro e Oliveira (2011).

Tais acervos são: o Acervo Dantas Júnior, composto por documentos de cunho mais formal oriundos de escreventes com alto nível de escolaridade, sendo considerado amostra representativa do PB culto; o conjunto de cartas Correspondências Amigas: o acervo de Valente, Bahia, composto por manuscritos de cunho informal, em sua maioria, produzidos por escreventes representantes de um PB semiculto e, por fim, o Acervo Cartas em Sisal: Riachão do Jacuípe, Conceição do Coité e Ichu, constituído por cartas de cunho informal manuscritas por escreventes adultos em níveis iniciais de aquisição da escrita, oriundos da zona rural das cidades de Riachão do Jacuípe, Conceição do Coité e Ichu, localizadas no interior da Bahia. Os escreventes do último acervo são classificados por Santiago (2019) como inábeis, sendo esses documentos considerados amostras representativas do PB popular.

A escolha dos corpora, baseia-se no que Lucchesi (2001) aponta a respeito da realidade sociolinguística brasileira, que é caracterizada pela polarização decorrente da formação histórica, política, econômica e social do Brasil. O autor chama atenção para a ideia do PB ser uma língua polarizada, visto que, percebe-se a existência de normas cultas, concentradas nos centros urbanos e entre falantes com maior grau de escolaridade, e normas populares, comumente encontradas nas áreas rurais, nas periferias dos grandes centros e entre falantes de menor grau de escolaridade. Lucchesi (1994) afirma que as normas cultas estariam mais vulneráveis às influências oriundas do PE, devido à escolarização institucionalizada, e que as normas vernáculas, por não sofrerem tanta pressão de uma norma padronizada baseada no português da Europa, expressariam o PB. O autor acrescenta ainda que tais normas tenderiam a se aproximar no decorrer do tempo, como consequência dos 
processos de industrialização e urbanização ocorridos no Brasil durante o século XX. Além disso, vale dizer que esses corpora têm relevância em acordo com o que Mattos e Silva (2008b) ressalta sobre a importância de reconstruir a história linguística do PB, através de estudos de documentos oriundos não apenas da vertente urbana, mas também das variedades rurais com passado não necessariamente marcado pela presença africana.

A fim verificar a hipótese de Lucchesi (1994), Carneiro (2016) realiza um estudo sobre a colocação dos clíticos nas orações finitas em corpora de linguagem oral de indivíduos da cidade de Feira de Santana - Bahia, extraídos do banco de dados do projeto A língua portuguesa no semiárido baiano, fase III. As amostras são constituídas de fala informal de falantes cultos, sujeitos à pressão do $\mathrm{PE}$ por processos de escolarização, e de falantes pouco ou não escolarizados, pouco sujeitos ou não sujeitos a um uso do PE. O resultado obtido por Carneiro (2016) foi de generalização da próclise em todos os contextos considerados nas falas de todos os indivíduos, evidenciando, assim, a aproximação das vertentes sugerida por Lucchesi (1994).

Assim o objetivo com a descrição da colocação dos clíticos em orações finitas com verbo único e grupos verbais, considerando os contextos relevantes que distinguem o PB do PE com base em Galves, Britto e Paixão de Souza (2005), é o de verificar se a hipótese da aproximação das vertentes se confirma nos documentos do século XX provenientes da escrita de indivíduos do sertão baiano. Considerando que o resultado de Carneiro (2016) foi de $100 \%$ de próclise em todos os contextos de colocação, o que confirma a aproximação das vertentes na modalidade oral, pretende-se observar se o mesmo acontece na modalidade escrita.

Para isso, os dados de colocação dos clíticos em orações finitas com verbo único e grupos verbais foram coletados nos corpora, de forma manual e exaustiva, depois esses dados foram classificados de acordo com os contextos relevantes pela distinção do PB e PE, a saber: i) sentenças com verbo único: verbo em posição inicial absoluta e verbo antecedido de sujeito neutro, sintagma preposicional ou sintagma adverbial, com advérbios 
não atratores de próclise, e ii) sentenças com grupos verbais: observando a subida do clítico ou a não subida do clítico com colocação em próclise ao segundo verbo, a chamada colocação de inovação brasileira. Assim, a fim de obter tabela com percentual de ocorrências, os dados foram codificados e submetidos ao programa Goldvarb- $X$ (SANKOFF; TAGLIAMONTE; SMITH, 2005), realizando rodadas separadas para cada acervo, visto que eles representam distintas vertentes do $\mathrm{PB}$, considerando o nível de escolaridade dos escreventes e tomando como base o continuum de Lucchesi (2015).

A hipótese desse estudo é a de que as vertentes podem revelar padrões distintos de colocação entre os documentos representativos das vertentes cultas, semicultas e populares, visto que, devido ao fato de constituírem corpora de linguagem escrita, em que o uso da língua se dá de forma monitorada, a norma padronizadora pode exercer maior influência entre os escreventes das normas culta e semiculta. Supõe-se também que nas amostras de língua popular os padrões de colocação do PB sejam mais evidentes, uma vez que os escreventes são adultos pouco ou não escolarizados em fases iniciais de aquisição da escrita.

Por fim, deve-se acrescentar que este estudo segue os fundamentos da Linguística História em perspectiva sócio-histórica (MATTOS E SILVA, 2008) e é realizado com base nas agendas de pesquisa propostas pelo Projeto Para História do Português Brasileiro (PHPB), estruturadas de acordo com Lobo (2009) em três campos interligados: a) o campo histórico-filológico, que visa à constituição de corpora diacrônicos de documentos escritos no Brasil, o qual, para esta pesquisa, foi desenvolvido por Santiago (2019) e Carneiro, Oliveira e Almeida (2011) na constituição dos corpora aqui utilizados; b) o campo de estudos das mudanças linguísticas através da análise dos corpora constituídos que, neste trabalho, abrange o estudo da colocação dos clíticos em sentenças finitas com verbo único e grupos verbais; e c) o campo que se detém na reconstrução da história social linguística do Brasil, contemplado nesta pesquisa através da descrição da sintaxe dos clíticos por vertentes do $\mathrm{PB}$, considerando aspectos sociais das amostras representativas das vertentes culta, semiculta e popular do sertão baiano do século XX. 


\section{A realidade sócio-histórica do PB: as normas cultas e populares}

Como já dito, para Lucchesi (2001) a realidade sociolinguística brasileira é caracterizada pela polarização decorrente da formação histórica, política, econômica e social do Brasil. Essa polarização é consequência da realidade sócio-histórica do Brasil, que foi marcada, segundo Mattos e Silva (2004), pelo multilinguismo/multialetalismo generalizado decorrente do intenso contato entre línguas no período da colonização brasileira. Lucchesi (2015) aponta que o período caracterizado por esse multilinguismo “[...] se estende do efetivo início da colonização portuguesa, ocorrido em São Paulo, com a fundação da Vila de São Vicente, em 1532, até meados de 1695 [...]" (p. 85) e acrescenta que, nessa época, a polarização sociolinguística era muito radical, já que, de um lado, havia uma minoria de falantes do português, língua de prestígio e, de outro, estavam as segregadas línguas africanas, indígenas e as variedades com intensas modificações estruturais do português falado por descendentes de negros escravizados e índios.

Segundo Mattos e Silva (2004), havia no Brasil a presença concomitante de variedades como

a. O português europeu na sua dialetação diatópica, diastrástica e diacrônica, que teria ao longo do período colonial um contingente médio de $30 \%$ da população brasileira [...];

b. As línguas gerais indígenas, que, plurais e dialetalizadas, poderiam até confundir-se com o português geral brasileiro nas áreas geográficas delimitáveis em que se difundiram;

c. O português geral brasileiro, antecedente histórico do português popular brasileiro que, adquirido na oralidade e em situações de aquisição imperfeita, é difundido pelo geral do Brasil, sobretudo pela presença maciça da população africana e dos afro-descendentes que perfizeram uma média de mais de $60 \%$ da população por todo o período colonial. (MATTOS E SILVA, p. 90) 
Dessa maneira, é possível perceber o intenso contato entre línguas e a grande propensão ao surgimento de variedades linguísticas diversas. Lucchesi (2015) afirma ainda que, neste período, o português era restrito apenas à administração da colônia e às escolas dos jesuítas, e acrescenta que, em São Paulo, os descendentes de indígenas com colonizadores falavam a língua geral paulista, de base tupi. No Maranhão e no Pará, antiga província do Grão-Pará, era falada outra língua geral de base tupinambá; na Bahia, devido ao grande contingente de negros escravizados, as línguas banto eram faladas por metade dos habitantes, sendo o quimbundo a mais falada. Além disso, o contexto favorecia a existência de línguas pidgins ou crioulas nos quilombos.

Lucchesi (2015) aborda também que o português começou a ser disseminado pelo país devido a dois momentos históricos que atraíram grande quantidade de portugueses para a colônia. O primeiro ocorreu em fins do século XVII motivado pelas descobertas das minas de ouro e diamantes, em que muitos portugueses vieram para o Brasil, acreditando estar na colônia e nessas minas a promessa de riqueza. Esse fato levou grande quantidade de pessoas para o interior do país e, consequentemente, expandiu os horizontes da língua portuguesa. O segundo momento aconteceu em 1808, com a chegada da Corte portuguesa no Rio de Janeiro, atraindo, além dos membros da corte, os comerciantes e população de diversas classes de Portugal. Esse acontecimento contribuiu para a alteração de aspectos sociais, culturais e econômicos do país, além de induzir ao aumento da urbanização do Rio de Janeiro. Vale ressaltar, ainda, que o fim do tráfico negreiro e o constante extermínio de grande parte da população indígena foram fatores que impulsionaram uma diminuição do multilinguismo no Brasil, colocando a língua portuguesa em um lugar de destaque em relação às demais.

Como aponta Lucchesi (2015), é importante ressaltar que a variedade do português mais intensamente difundida no Brasil foi a aprendida de forma assistemática pelos descendentes dos escravos africanos e demais população de imigrantes e índios. Sobre isso, Lucchesi (2015) chama a atenção para o fato de que esse português disseminado pelo país "[...] não era o português 
'castiço' da elite colonial, mas o português 'estropiado' por sua aquisição precária e pela nativização mestiça" (p. 92). Tal fato contribuiu para compor a polarização sociolinguística existente ainda hoje no Brasil, e sobre isso o autor acrescenta que

Nesse processo, a polarização sociolinguística do Brasil logo passou a opor a língua dos colonizadores portugueses e de seus filhos brasileiros às variedades mais ou menos defectivas de português faladas como segunda língua por índios aculturados e africanos escravizados, juntamente com uma versão nativizada desse português defectivo, que se foi tornando a língua materna dos filhos mestiços e endógamos desses índios e africanos. Define-se, assim, em suas grandes linhas, o processo histórico que deu origem à polarização sociolinguística do Brasil. (LUCCHESI, 2015, p. 92)

Assim, foi a partir do cenário da Revolução Industrial em 1930, com o aumento da urbanização através do grande contingente migratório da população rural para as cidades, e a posterior democratização da escolarização, com a criação de escolas públicas em todo o território nacional, que a intensidade da polarização sociolinguística no Brasil iniciou um processo que Lucchesi (2015) chama de nivelamento linguístico.

Entretanto, Lucchesi (2015) acrescenta que, ainda que por meio desse nivelamento o abismo que tange a polarização linguística no Brasil tenha se estreitado, é importante enfatizar que ele não atingiu maiores proporções devido ao desenvolvimento tardio do país, às condições muitas vezes precárias das instituições públicas de ensino, além da concentração de renda nas mãos de uma elite minoritária da população, conservando, assim, um cenário de polarização social que ainda se reflete na língua.

Desse modo, Lucchesi (2015) aponta que o modelo da polarização sociolinguística do Brasil é orientado nos contrastes entre os padrões linguísticos das classes altas e os padrões das classes marginalizadas. Com isso, baseando-se na ideia de continuum de Bortoni-Ricardo (2005), o autor 
levanta a ideia de aplicação de um modelo de três continua, em que em um ponto extremo, tem-se a norma popular dos falantes imersos na oralidade e das comunidades rurais mais isoladas, que possuem uma variação estilística bastante reduzida, enquanto no outro extremo se tem a norma culta, representada por falantes com altos graus de escolaridade dos grandes centros urbanos com extenso repertório de variação estilística, situando entre esses dois extremos um continuum de níveis intermediários.

Então, Lucchesi (2015) afirma que "à medida que se passa do polo extremo da norma popular para o ápice da norma culta, cresce progressivamente o grau de urbanização e letramento, bem como o espectro da variação estilística" (p.153), e, com base nisso, revela três cenários sociolinguísticos, discriminados pelo autor em uma escala rural $>$ rurbano $>$ urbano. Assim, são considerados do cenário rural os indivíduos analfabetos ou semianalfabetos de comunidades rurais menos/mais isoladas, no cenário rurbano, estão os habitantes de baixa ou pouca escolaridade das pequenas cidades do interior e emigrados do campo para a periferia das grandes cidades, e, por fim, o cenário urbano é formado por membros de baixa ou pouca escolaridade da periferia das grandes cidades e bairros populares mais centrais e tradicionais, trabalhadores e operários qualificados das cidades e centros industriais, comerciantes e trabalhadores técnicos administrativos das pequenas, médias e grandes cidades e altos funcionários do executivo e do judiciário, profissionais liberais e intelectuais das pequenas, médias e grandes cidades.

Em acordo com a ideia de polarização linguística trazida por Lucchesi (1994; 2001; 2015), Mattos e Silva (2008b) afirma que a “designação português brasileiro, abrange-se correntemente o chamado português popular ou vernáculo brasileiro e o português culto brasileiro, ou seja, as normas vernaculares e as normas cultas, na terminologia de Lucchesi” ( $p$. 13). Assim, a autora chama atenção para a necessidade de romper com a ideia generalizante de "português brasileiro", como se existisse uma única vertente, homogênea, desse português e defende que o PB é heterogêneo, polarizado e plural.

Confluência. Rio de Janeiro: Liceu Literário Português, n. 61, p. 299-334, jul.-dez. 2021 
Com base nisso, Mattos e Silva (2008b) coloca que o português europeu seria o antecedente histórico do português brasileiro culto, que começa a se definir na segunda metade do século XVIII devido às diretrizes políticoculturais implantadas por Marquês do Pombal e que, em contrapartida, o português popular brasileiro é originado do português geral brasileiro, oriundo do multilinguismo decorrente do contato entre o português europeu, as línguas indígenas e africanas no século XVI.

\section{A colocação dos clíticos: um breve percurso histórico}

A colocação dos clíticos em orações finitas é um fenômeno linguístico considerado importante por muitos estudiosos (PAGOTTO, 1992; MARTINS, 1994; CARNEIRO, 2005; MARTINS, 2009; GALVES E CARNERO, 2010; ANDRADE, 2010; REIS, 2011) devido às disparidades encontradas ao contrapor o PB com o PE. Tais disparidades acabam por retratar aspectos relevantes, evidenciando mudanças ocorridas historicamente que são fundamentais para a elaboração de hipóteses que colaborem para a compreensão da periodização do português, além de revelar algumas questões que envolve a formação das vertentes cultas e populares do PB, visto que a colocação dos clíticos realizada por brasileiros cultos em ambientes de formalidade se aproxima dos padrões do PE com uso considerável da ênclise, ao passo que em situações de espontaneidade ou na linguagem de brasileiros que utilizam as normas populares, a próclise é evidente.

Nas construções formadas por único verbo, ver-se na tradição gramatical e situações de escrita formal que em orações em que o verbo está em posição inicial absoluta (sentenças V1) a colocação deve ser de ênclise (exemplo 1). A ênclise nesse contexto é a única colocação possível no $\mathrm{PE}$, visto que há no $\mathrm{PE}$ a restrição da possibilidade de um termo átono iniciar uma sentença. Já o PB apresenta caracterização distinta, visto que em situações de fala espontânea a preferência é pela próclise (exemplo 2), ocorrendo por vezes a completa generalização da colocação pré-verbal, 
como aponta Carneiro (2016). Além disso, na escrita de brasileiros, é possível perceber uma variação entre a colocação enclítica e proclítica. Assim, como a próclise em início de sentença não é aceita no $\mathrm{PE}$, esse contexto sintático evidencia uma das diferenças que caracterizam o PE e o PB, fazendo-se relevante (CARNEIRO, 2005; PAGOTTO e DUARTE, 2005; CARNEIRO e GALVES, 2006). Os exemplos que seguem ilustram a colocação dos clíticos nesse contexto.

(1) sinto-me satisfeito em lhe escrever sob $\mid$ a luz elétrica que inaugurei no meu Caetité|

(LEMOS, 2019, p. 83 ex original 94)

(2) te desejo muita saúde, paz, [ilegível] e sucesso em tudo.|| Da amiga que te gosta muito|

(LEMOS, 2019, p. 83 ex original 97)

As sentenças raízes principais afirmativas com verbo antecedido de um sujeito neutro (exemplos 3 e 4), sintagma preposicional (exemplos 5 e 6) e sintagma adverbial, formado por advérbios não atratores de próclise (exemplos 7 e 8), são outros ambientes sintáticos de relevância nas construções formadas por verbo único. Galves, Britto e Paixão de Souza (2005) classifica esse contexto como Contexto de variação I, que é assim denominado porque se apresentava como variável, com próclise amplamente majoritária, no Português Clássico (doravante $\mathrm{PCl}$ ). Posteriormente, passa-se a perceber um aumento considerável da ênclise até se caracterizar por ênclise generalizada no PE (cf. Martins, 1994). No PB, entretanto, este se configura como um contexto de próclise generalizada em situações de fala espontânea (cf. Carneiro, 2016) e de variação na modalidade escrita, devido as pressões da norma padronizadora (GALVES E CARNEIRO, 2010). As sentenças a seguir exemplificam estes contextos. 
(3) ela perguntou-me se você tinha| falado alguma coisa sobre ela eu disse que| não.

(LEMOS, 2019, p. 115 ex original 291)

(4) $\mathrm{eu} \mid$ me choquiei pençando que era| por loquise mas era roindade (LEMOS, 2019, p. 115 ex original 292)

(5) Em visita cordeal, asseguro-lhe e á digna Familia alegres festas $\mid$ e felicidades no anno a entrar.|

(LEMOS, 2019, p. 117 ex original 316)

(6) por| imfilisidade da minha vida me| acho na trite separação

(LEMOS, 2019, p. 118 ex original 320)

(7) hoje achei-a e logo fui te| escrever.

(LEMOS, 2019, p. 118 ex original 324)

(8) Agora te envio esse requerimento, pedindo a| você executal-o com a tua| acostumada bondade e urgencia| precisa.

(LEMOS, 2019, p. 118 ex original 326)

Ao enfatizar construções formadas por grupos verbais, que são compostas por um verbo finito e outro infinito, o comportamento dos clíticos na história do português, instiga os pesquisadores em decorrência da perda da capacidade, no PB, desses elementos estarem adjacentes ao verbo finito em sentenças não passivas, ao passo que no PE essa colocação, por vezes, é obrigatória. Tal fenômeno, denominado por Clitic Climbing ou subida do clítico, dar-se quando um clítico argumento do verbo temático, ou principal, se encontra atrelado ao primeiro verbo da construção, do qual esse clítico não é complemento. 
Além disso, é importante ressaltar que há no PB uma colocação não registrada ao longo da história do português, essa colocação conhecida como inovação brasileira, acontece quando o clítico aparece ligado, em próclise, ao verbo infinito. A seguir, é possível encontrar as colocações nas construções com grupos verbais.

(9) A dias que tenho tido grande desejo| de pessoalmente entender-me com Doutor João-|zinho, porem não me tem sido possivel.

(LEMOS, 2019, p. 164 ex original 576)

(10)Aqui estou passando bem. Não| melhor porque não estou-lhe vendo a| todo momento.|

(LEMOS, 2019, p. 164 ex original 574)

(11)Ah! já estava me esquecendo, tá faltando papel paltado em Valen-|te é?

(LEMOS, 2019, p. 9 ex original 151)

(12)Hoje me lembro| mais de você.|| Te desejo tudo de bom que pode| existir nesse mundo, e que saiba| aproveitá-lo todos os minutos e| horas desta felicidade

(LEMOS, 2019, p. 166 ex original 594)

Assim, de acordo com Carneiro (2005), a caracterização da colocação dos clíticos no período tido, pela periodização tradicional, como $\mathrm{PCl}$ é de próclise ao verbo finito categórica nos contextos em que a colocação pré-verbal estava favorecida (exemplo 9). No PE, essa colocação ocorre em sentenças dependentes, negativas ou principais com a presença de quantificadores, modificadores ou advébios modais, elementos chamados por Martins (1994) de atratores de próclise. Conforme Pagotto (1992), nas sentenças com ausência de atratores a próclise ao primeiro verbo passa a variar, no PE, com a ênclise ao verbo infinito (exemplo 12), que é encontrado de forma majoritaria no PE. 
Quanto à colocação com ênclise ao primeiro verbo (exemplo 10), Andrade (2010) aponta que essa é uma colocação marginal, mesmo em dados das variedades europeias do português, sendo comum a variação entre a próclise ao primeiro verbo e ênclise ao segundo.

A construção de próclise ao segundo verbo (exemplo 11) é a colocação típica do PB. Esse tipo de construção é encontrada em dados de Pagotto (1992) em períodos posteriores ao século XIX, enquanto Carneiro (2005) observa um percentual significativo da inovação brasileira nas Cartas Brasileiras desde a segunda metade do século XIX. Martins (2009), Reis (2011) e Lemos (2019) apontam que no século XX a inovação brasileira possui colocação cada vez mais ampla e majoritária.

\section{Aspectos teórico-metodológicos e os corpora da pesquisa}

Este estudo em Linguística Histórica segue uma perspectiva Sóciohistórica (MATTOS E SILVA, 2008a) e é constituído a partir das agendas de pesquisa propostas pelo Projeto para História do Português Brasileiro (PHPB), estruturadas de acordo com Lobo (2009) em três campos interligados de pesquisa: a) campo histórico-filológico, que visa à constituição de corpora diacrônicos de documentos escritos no Brasil; b) campo de estudos das mudanças linguísticas através da análise dos corpora constituídos; c) campo que se detém na reconstrução da história social linguística do Brasil.

Assim, no que tange ao campo (a), este trabalho tem como suporte os trabalhos realizados por Santiago (2019) e Almeida, Carneiro e Oliveira (2011), visto que os corpora aqui utilizados foram devidamente constituídos em edição semidiplomática fac-similar pelas pesquisadoras, realizando tal edição de acordo com as normas do PHPB em caráter conservador, apenas expandindo as abreviações. O campo (b) é desenvolvido, neste trabalho, a partir do estudo da colocação dos clíticos em sentenças finitas com verbo único e grupos verbais nos corpora. Além disso, este trabalho também contribui para o campo (c), no que se refere ao estudo dos dados 
separados por vertentes do PB, tendo em vista que os corpora analisados são constituídos de cartas manuscritas por escreventes de níveis diversos de escolaridade separados como representantes de um PB culto, semiculto e popular, conforme aponta Lucchesi (2015).

Os corpora utilizados nesta pesquisa são constituídos de 244 cartas e 10 cartões, datados de anos do século XX e manuscritos por indivíduos nascidos em cidades localizadas no semiárido baiano. Esses documentos pertencem a 3 acervos, caracterizados por conterem aspectos sociais distintos entre si, e fazem parte do banco de textos do Corpus Eletrônico de Documentos Históricos do Sertão (CE-DOHS/UEFS). Como já dito, tais acervos são: o Acervo Dantas Júnior (1902 - 1962), as Correspondências Amigas: o Acervo de Valente, Bahia (1980 - 1993) e o Acervo Cartas em Sisal: Riachão do Jacuípe, Conceição do Coité e Ichu (1906 - 2000).

O Acervo Dantas Júnior é composto por cartas destinadas à Dantas Júnior, descendente de uma família tradicionalmente política do interior da Bahia e que atuou no cenário político desde os 23 anos de idade como deputado estadual no contexto da República Velha. As cartas desse acervo são, de forma majoritária, manuscritas por indivíduos com altos níveis de escolaridade, tratando-se de juízes, advogados, professores universitários e indivíduos de altos cargos públicos. De maneira geral, os conteúdos das cartas retratam acontecimentos políticos, pedidos de favores, de cargos públicos ou de apoio político, além de agradecimentos pela realização dos favores. Deste acervo, foram utilizadas 118 cartas, das quais 52 apresentam linguagem mais informal, enquanto as demais revelam caráter mais formal.

As Correspondências Amigas: o Acervo de Valente, Bahia constituem um conjunto de cartas e cartões pessoais destinados a Adelmário Carneiro Araújo, baiano morador da cidade de Valente e que, através dos serviços dos Correios, buscava conhecer pessoas de várias cidades do Brasil. Os escreventes desse acervo, segundo Almeida, Carneiro e Oliveira (2011), era jovens com idades entre 20 e 35 anos, estudantes do Ensino Fundamental ou Médio e representantes de um português semipopular ou semiculto. $\mathrm{O}$ 
conteúdo das cartas, notavelmente de cunho informal, retratava expressões de saudades, envio de notícias e novidades nas rotinas dos escreventes, além de combinações de encontros e comentários sobre esses encontros. Deste conjunto de documentos foram utilizados para esta pesquisa 35 cartas e 10 cartões.

Por fim, o Acervo Cartas em Sisal: Riachão do Jacuípe, Conceição do Coité e Ichu é constituído por 91 cartas pessoais trocadas entre escreventes adultos em fases iniciais de aquisição da escrita, os quais Santiago (2019) classificou como indivíduos inábeis. Os remetentes desses documentos são nascidos e/ou residentes de zonas rurais dos municípios baianos de Riachão do Jacuípe, Conceição do Coité e Ichu. Há neste acervo apenas 3 cartas escritas com linguagem formal, todas relativas à pedidos de casamento, as demais são caracterizadas pela informalidade na escrita. De modo geral, as cartas trazem como conteúdo o envio de notícias entre parentes e amigos, expressão de saudades e pedidos de favores.

Para realizar este trabalho os dados foram coletados exaustivamente, de forma manual, e classificados de acordo com os contextos sintáticos. Nas construções com verbo único, a classificação seguiu as tendências de colocação dos clíticos no decorrer da história do português, em contextos considerados mais relevantes por distinguir o $\mathrm{PB}$ e o $\mathrm{PE}$, a saber: a) contexto de ênclise categórica no $\mathrm{PE} \mathrm{e} \mathrm{b)} \mathrm{contextos} \mathrm{variáveis} \mathrm{no} \mathrm{PCl}$ (os quais evidenciam a próclise majoritária no PB e a ênclise categórica no PE). Nos grupos verbais foram consideradas a subida e não subida dos clíticos no corpus, em que se observa a frequência da colocação de inovação brasileira em contraste com as demais colocações, que são mais comuns no PE.

Visto que a descrição dos dados se dá por vertentes do $\mathrm{PB}$, foi considerado nesta pesquisa o nível de escolaridade dos escreventes, em que as amostras representativas do PB culto são os manuscritos oriundos de indivíduos com altos níveis de escolaridade, ou com ensino superior; as amostras do PB semiculto são representadas por escreventes com níveis médios de escolaridade, ou indivíduos que possuem ensino Fundamental ou Médio; e as amostras do PB popular são representadas pelas cartas 
escritas por adultos em fases iniciais de aquisição da escrita pouco ou não escolarizados, essa classificação segue o proposto por Lucchesi (2015). Vale ressaltar ainda, que não foi possível identificar de forma mais específica o nível de escolaridade de alguns remetentes, os quais possuem documentos que fazem parte do Acervo Dantas Júnior, no entanto, por este acervo se caracterizar por ser constituído de documentos de indivíduos com condições socioeconômica alta e cargos que exigem maiores níveis de escolaridade, infere-se que estes são representantes do PB culto, entretanto, a fim de manter a transparência desses dados, os resultados desses escreventes são trazidos com a denominação Sem identificação.

Assim, os dados foram codificados e submetidos ao programa Goldvarb-X (SANKOFF; TAGLIAMONTE; SMITH, 2005), a fim de obter resultados quantitativos em valor percentual nos diferentes contextos de colocação sintática. Vale ressaltar que, por esta não ser uma pesquisa de cunho variacionista não foram calculados os pesos relativos dos fatores, visto que o interesse principal é saber como se dá a colocação dos clíticos em contextos sintáticos específicos por diferir o $\mathrm{PE}$ do $\mathrm{PB}$ na história do português em amostras representativas de três diferentes vertentes do PB.

\section{Resultados: a colocação dos clíticos em construções com verbo único}

Nas 254 cartas que compõem os corpora desta pesquisa, foram encontrados 647 dados de clíticos em construções formadas por verbos únicos em sentenças finitas. Desse total, 207 dados, ou 32\% das ocorrências, são de ênclise, enquanto os outros 440 dados, que corresponde à $68 \%$ das ocorrências, são de próclise. Serão apresentados, assim, os resultados separados por contextos que revelam certos padrões de colocação verificados ao longo da história do português (cf. Martins, 1994; Carneiro, 2005; Galves, Britto e Paixão de Souza, 2005), bem como a colocação por escolaridade dos escreventes e formalidade/informalidade das cartas. 
O contexto de verbo em posição inicial nas sentenças (sentenças V1), revela ser um importante aspecto que caracteriza o PB (cf. Martins, 1994; Pagotto, 1992; Carneiro, 2005; Martins, 2009; e outros), visto que, não havendo um elemento precedente ao verbo que possa atrair o clítico à colocação préverbal, algumas línguas românicas apresentam o impedimento de que o clítico apareça no início da sentença, essa restrição existe no PE, enquanto que, em outras línguas românicas esse impedimento inexiste, tal qual o PB. Assim, separando os dados correspondentes à posição inicial absoluta daquelas em que vocativos e/ou saudações antecedem o verbo, apenas para tornar claro os resultados, a tabela que segue evidencia os resultados deste contexto.

Tabela 1. Colocação ênclise/próclise em sentenças V1 nas Cartas do Sertão Baiano (Século XX)

\begin{tabular}{lccc}
\hline \multicolumn{1}{c}{ SENTENÇAS V1 e \#V } & $\begin{array}{c}\text { ENCLISE (V-cl) } \\
\text { Dados } / \\
\text { Percentual }\end{array}$ & $\begin{array}{c}\text { PRÓCLISE (cl V) } \\
\text { Dados } / \\
\text { Percentual }\end{array}$ & $\begin{array}{c}\text { TOTAL } \\
\text { Dados } / \\
\text { Percentual }\end{array}$ \\
\hline Posição inicial absoluta & $67 / 89.3 \%$ & $8 / 10.7 \%$ & $75 / 87.2 \%$ \\
\hline Com vocativos ou saudações & $5 / 45.5 \%$ & $6 / 54.5 \%$ & $11 / 12.8 \%$ \\
\hline TOTAL & $72 / 83.7 \%$ & $14 / 16.3 \%$ & 86 \\
\hline
\end{tabular}

Desse modo, como na escrita a colocação enclítica é comum entre escreventes brasileiros, devido ao fato de haver monitoramento da língua nesta modalidade, os 14 dados de próclise encontrados evidenciam uma quantidade relevante, sobretudo para notar a presença de uma colocação muito típica do PB nos corpora. Ao analisar separadamente esses resultados por escolaridade do escrevente, tem-se o seguinte gráfico. 


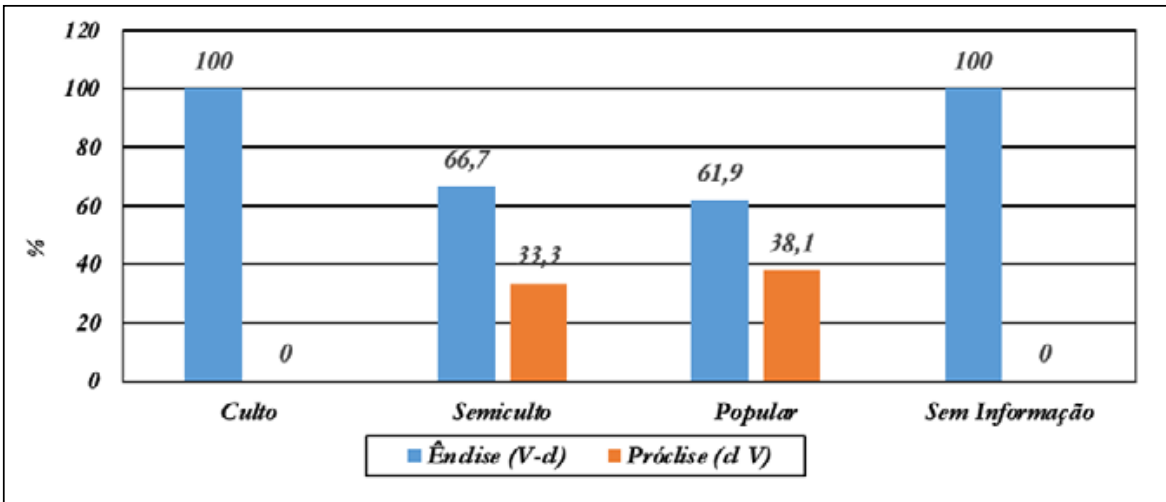

Gráfico 1. Colocação ênclise/próclise em sentenças V1 por escolaridade do escrevente nas Cartas do Sertão Baiano (Século XX)

Nota-se nos resultados por escolaridade do escrevente, a completa ausência de próclise em cartas de cultos, comprovadamente, e de cultos, por inferência a partir de outras informações sociais dos escreventes, denominado de "sem informação". É interessante perceber que os dados de próclise neste contexto são observados em cartas de escreventes semicultos e pouco ou não escolarizados. Isso mostra que a restrição do clítico em início de sentença é mais evidente na escrita daqueles que possuem um maior nível de escolaridade, sendo interessante notar que a ausência total da próclise entre esses escreventes revela indícios que confirmam a ideia de Matos e Silva (2008b) ao relacionar o PE como antecedente histórico do PB culto, já que essa vertente segue padrões de colocação do PE.

Entretanto, ainda que a próclise esteja presente na escrita de semicultos e representantes do PB popular desses corpora, a diferença entre o percentual da ênclise não apresenta uma grande diferença entre cultos, semicultos e não escolarizados, visto que, a colocação é de $66,7 \%$ em documentos de semicultos e $61,9 \%$ em manuscritos de não escolarizados, ou seja, a colocação pós-verbal é ainda majoritária entre esses escreventes. 
Galves, Britto e Paixão de Souza (2005) denomina de contexto de variação $I$, as orações raízes principais afirmativas com verbo antecedido de sujeito neutro, sintagma preposicional ou sintagma adverbial, com advérbios não atratores de próclise (sentenças V2, quando o verbo estiver imediatamente precedido por um desses elementos ou $\mathrm{V}>2$ quando o verbo aparece antecedido por um desses elementos, porém, tal elemento é antecedido por algum outro elemento não atrator de próclise). Tal denominação ocorre devido a esse contexto sintático evidenciar a variação ênclise/próclise no $\mathrm{PCl}$ e, é considerado um importante contexto por apresentar ênclise categórica no PE e próclise categórica na fala espontânea do PB. A tabela a seguir ilustra os resultados desse contexto nos corpora.

Tabela 2. Colocação ênclise/próclise em contexto de variação I nas Cartas do Sertão Baiano (Século XX)

\begin{tabular}{|c|c|c|c|}
\hline $\begin{array}{l}\text { CONTEXTO DE } \\
\text { VARIAÇÃO I }\end{array}$ & $\begin{array}{c}\text { ÊNCLISE (V-cl) } \\
\text { Dados / } \\
\text { Percentual }\end{array}$ & $\begin{array}{c}\text { PRÓCLISE (cl V) } \\
\text { Dados / } \\
\text { Percentual }\end{array}$ & $\begin{array}{c}\text { TOTAL } \\
\text { Dados / } \\
\text { Percentual }\end{array}$ \\
\hline Sujeito Pronominal - V2 & $2 / 7.4 \%$ & $25 / 92.9 \%$ & $27 / 23.89 \%$ \\
\hline Sujeito Pronominal $-\mathrm{V}>2$ & 0 & $15 / 100 \%$ & $15 / 13.27 \%$ \\
\hline Sujeito DP - V2 & $11 / 47.8 \%$ & $12 / 52.2 \%$ & $23 / 20.35 \%$ \\
\hline Sujeito DP $-\mathrm{V}>2$ & $3 / 30 \%$ & $6 / 66.7 \%$ & $9 / 7.96 \%$ \\
\hline Sujeito com O. relativa $-\mathrm{V} 2$ & $3 / 100 \%$ & 0 & $3 / 2.65 \%$ \\
\hline Sujeito com O.relativa $-\mathrm{V}>2$ & $1 / 100 \%$ & 0 & $1 / 0.88 \%$ \\
\hline Sintagma Preposicional - V2 & $8 / 72.7 \%$ & $3 / 27.3 \%$ & $11 / 9.73 \%$ \\
\hline Sintagma Preposicional $-V>2$ & $4 / 57.1 \%$ & $3 / 42.9 \%$ & $7 / 6.24 \%$ \\
\hline Advérbio Não Modal - V2 & $4 / 44.4 \%$ & $5 / 55.6 \%$ & $9 / 7.96 \%$ \\
\hline Advérbio Não Modal - V>2 & $2 / 25 \%$ & $6 / 75 \%$ & $8 / 7.07 \%$ \\
\hline TOTAL & $38 / 33.7 \%$ & $75 / 66.3 \%$ & 113 \\
\hline
\end{tabular}


De modo geral, os dados deste contexto revelam a ocorrência de variação com uma colocação maior de próclise (66,3\%). Além disso, sobre os ambientes em que o verbo é antecedido por um sujeito neutro, Lobo (1992) aponta que a próclise é categórica com sujeitos pronominais que, segundo a autora, caracteriza o PB. Martins (2008) percebe, em seus dados, a alta frequência da próclise em sentenças com sujeito pronominal desde o século XIX, enquanto dados de sentenças com sujeito DP são variáveis. Com isso, o autor levanta a hipótese de que a mudança que origina o PB aparece inicialmente em contextos com sujeitos pronominais.

Nos resultados referentes a esses contextos nos corpora dessa pesquisa, percebe-se uma aproximação significativa com os resultados observados por Lobo (1992) e (2008), visto que apenas 2 dados de ênclise foram encontrados entre as sentenças com verbo precedido apenas pelo sujeito pronominal (V2), um pertencente à escrita de cultos e outro de semicultos, e nenhum dado foi encontrado nas sentenças com verbo precedido de sujeito pronominal que é precedido por outro elemento ( $\mathrm{V}>2)$.

Além disso, ao observar os resultados da colocação em sentenças com sujeito DP, percebe-se que uma variação significativa se faz presente nos corpora, já que em sentenças V2 tem-se 11 dados de ênclise e 12 de próclise e nas $\mathrm{V}>2$ são 3 dados de ênclise e 3 de próclise, revelando novamente uma conformidade com os dados de Lobo (1992) e Martins (2008) e, consequentemente, indícios favoráveis à hipótese de Martins (2008).

O gráfico a seguir expressa os resultados do contexto de variação $I$ por vertentes do $\mathrm{PB}$. 


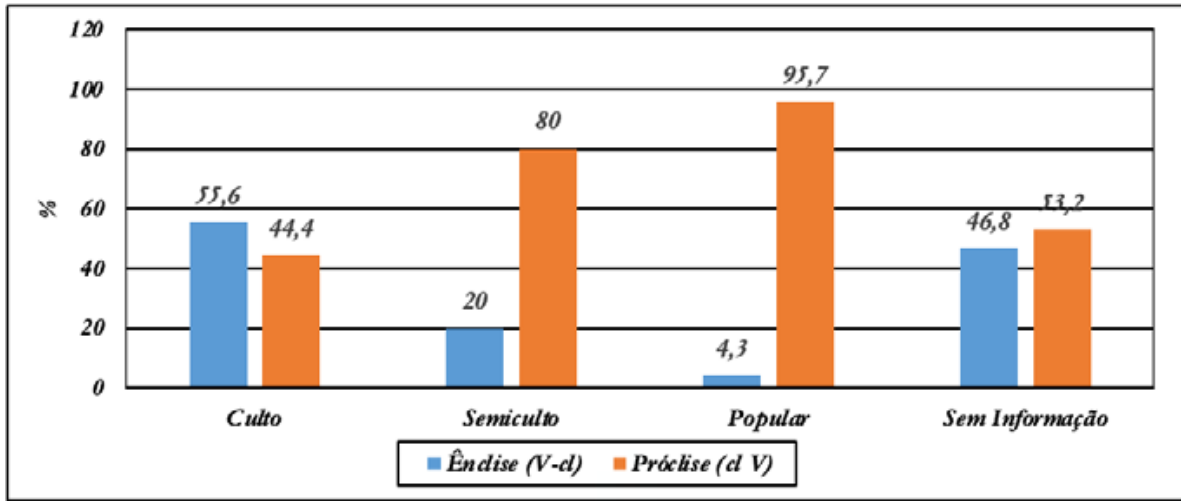

Gráfico 2. Colocação ênclise/próclise em contexto de variação I por escolaridade nas Cartas do Sertão Baiano (Século XX)

Nota-se que a próclise é majoritária na maioria dos escreventes, porém a ênclise apresenta ainda um alto índice entre escreventes comprovadamente cultos e escreventes cultos por inferência, apresentado no gráfico como "sem informação". Os 4,3\% de ênclise em dados de não escolarizados, representa apenas um dado de verbo antecedido de sujeito DP, ambiente sintático favorável à variação.

Observa-se ao realizar a comparação dos resultados por vertentes que apenas os escreventes comprovadamente cultos apresentam a colocação da ênclise superior à próclise. Carneiro (2005) ao analisar dados como esses, enfatiza a importância de um olhar atento na interpretação dos dados, visto que esses mesmos escreventes também realizam colocação pós-verbal em contextos de próclise categórica na história do português, o que indica uma colocação com pouca compreensão dos modelos, gerando a hipercorreção.

Assim, este contexto apresentou uma aproximação entre as vertentes dos semicultos e pouco e não escolarizados, enquanto os escreventes cultos, comprovadamente e por inferência, revelaram um uso mais considerável da ênclise. Considerando o trabalho realizado por Carneiro (2016) em dados extraídos de amostras da oralidade de cultos, semicultos e não escolarizados 
da cidade de Feira de Santana, localizada no semiárido baiano, e cujo resultado evidencia a próclise categórica em todos os contextos, é possível relacionar o percentual de ênclise apresentado nos corpora desta pesquisa à influência da norma padronizada, visto que há uma maior variação entre os escreventes com maiores graus de escolaridade, ou seja, sujeitos mais propensos à ênclise via escolarização institucionalizada.

\section{Resultados: a colocação dos clíticos em construções com grupos verbais}

Nas sentenças com grupos verbais foram encontrados um total de 245 dados, em que $75,5 \%$ deles constituem casos de não subida do clítico e $24,5 \%$ com subida. É importante ressaltar que os dados em contexto considerado ambíguo, ambiente de oração não dependente em que o clítico aparece entre o primeiro e o segundo verbo, sem marca gráfica que evidencie adjacência desse clítico a um dos verbos e, também, sem a presença de atratores de próclise na sentença, foram considerados nessa pesquisa como casos de próclise ao segundo verbo, também conhecido como colocação de inovação brasileira.

Essa decisão é decorrente de duas justificativas: a primeira delas é que de acordo com Andrade (2010) a ênclise ao primeiro verbo era uma colocação marginal mesmo em dados do PE datados do século XIX e XX, a segunda justificativa é decorrente das pesquisas que revelam a constante queda da subida do clítico nas sentenças não passivas no PB bastante considerável no século XIX (PAGOTTO, 1992; CARNEIRO, 2005) e amplamente predominante no século XX (MARTINS, 2009; REIS, 2011; LEMOS, 2019).

Partindo para os resultados, o quadro que segue retrata a quantidade e percentual de dados nas colocações, considerando que a adjacência do clítico em próclise ou ênclise ao primeiro verbo constitui a presença de subida do clítico e a próclise ou ênclise ao segundo verbo constitui a ausência de subida do clítico, foram também integradas sentenças com ou sem elementos na sentença (representados por X). 
Quadro 1. Distribuição dos dados das Cartas do Sertão Baiano por subida e não subida do clítico

\begin{tabular}{|l|l|}
\hline \multicolumn{1}{|c|}{ ESTRUTURAS } & \multicolumn{1}{c|}{ QUANTIDADE DE DADOS } \\
\hline SUBIDA DE CLÍTICO & 9 \\
\hline V-cl V & 1 \\
\hline V-cl X V & 50 \\
\hline cl-V V & 1 \\
\hline cl V X V & $\mathbf{6 1}$ \\
\hline TOTAL COM SUBIDA: & $\mathbf{2 4 , 5 \%}$ \\
\hline SEM SUBIDA DE CLÍTICO & \\
\hline V V-cl & 30 \\
\hline V X V-cl & 12 \\
\hline V X X V-cl & 5 \\
\hline V cl-V (Inovação Brasileira) & 124 \\
\hline V X clV (Inovação Brasileira) & 12 \\
\hline VXXclV (Inovação Brasileira) & 2 \\
\hline TOTAL SEM SUBIDA: & $\mathbf{1 8 5}$ \\
\hline TOTAL GERAL: & $\mathbf{7 5 , 5 \%}$ \\
\hline
\end{tabular}

Percebe-se no resultado geral de subida/não subida do clítico, uma preferência majoritária pela não subida nos corpora. Pagotto (1992), ao encontrar colocação do clítico em próclise ao verbo não-finito, colocação não atestada no $\mathrm{PE}$, sugere ter ocorrido, no $\mathrm{PB}$, uma mudança linguística que está relacionada à perda do movimento longo do clítico na sentença e, consequentemente, à queda na elevação do clítico. 
Nas ocorrências com subida do clítico, nota-se maior percentual da colocação pré-verbal. De acordo com Andrade (2010), a ênclise ao primeiro verbo é uma colocação marginal, mesmo em dados das variedades europeias do português, sendo comum a variação entre a colocação de próclise ao primeiro verbo e ênclise ao segundo verbo. Sobre a próclise ao verbo finito, esta era uma colocação categórica no $\mathrm{PCl}$, posteriormente, esse posicionamento passa a ser mais comum apenas com presença de atratores. No PB, com a queda da elevação do clítico, essa colocação passa a ser menos usada, como evidencia Pagotto (1992), desde o século XVIII.

Ao observar o tipo de verbo finito da sentença, nota-se que, dentre os verbos auxiliares e aspectuais há ocorrências de todos os tipos de colocação, sendo 30 dados de subida do clítico, 24 em auxiliares e $6 \mathrm{em}$ aspectuais, e 93 ocorrências sem subida, em que 9 ocorrem em aspectuais e 84 em verbos auxiliares. Nos resultados de modais e volitivos, tem-se 15 dados de subida do clítico, nos quais 12 são de próclise, sendo 1 com verbo volitivo e $11 \mathrm{com}$ modais, e 3 modais em ênclise ao verbo. Além disso, nota-se 51 casos de não subida, dos quais 19 são construções com volitivos, em que 10 são de ênclise e 9 da colocação de inovação brasileira, e 32 modais, em que em 11 deles o clítico está posicionado em ênclise e 21 são da posição inovadora. Nas construções formadas com verbos causativos e perceptivos, os dados apresentam 7 casos de próclise ao primeiro verbo e 23 da colocação de inovação brasileira. Nos verbos perceptivos, têm-se apenas 2 dados da colocação inovadora do PB.

Em relação aos verbos seguidos de preposição, Carneiro (2005) aponta que há uma tendência à ênclise ao segundo verbo com a preposição "a" e, com as demais preposições, há possibilidade de variação. Nos dados dessa pesquisa, encontra-se próclise ao segundo verbo, mesmo com a presença da preposição "a", o que pode indicar uma possível generalização da colocação de inovação brasileira. 
Ao observar os dados, separando-os entre a colocação de inovação brasileira e as colocações comuns ao PE, por escolaridade dos escreventes, é possível obter os seguintes percentuais:

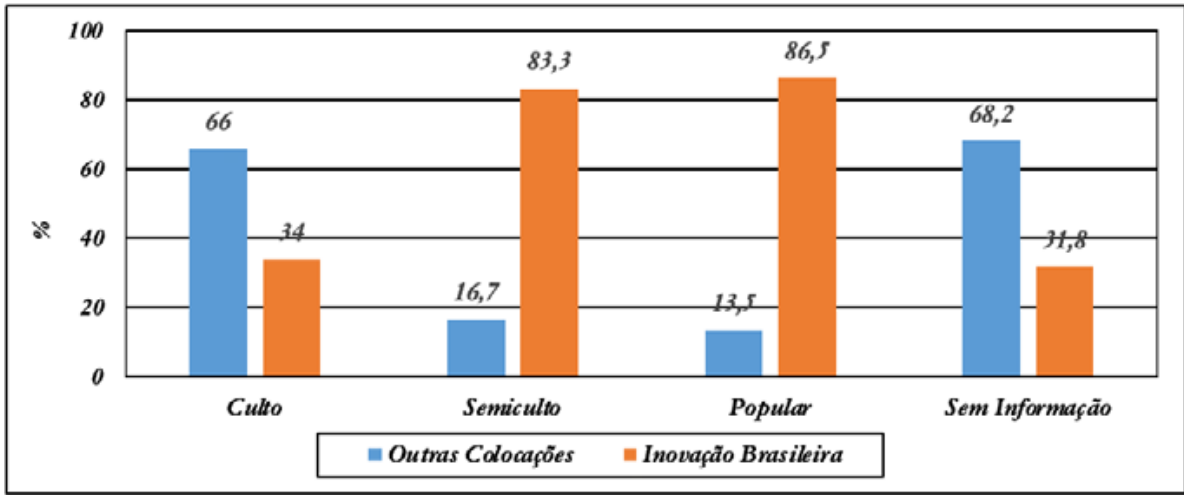

Gráfico 3. Frequência de inovação brasileira versus colocações do PE por escolaridade dos escreventes nas Cartas do Sertão Baiano (Século XX)

Nesses resultados, percebe-se uma maior frequência da inovação brasileira entre amostras de escreventes semicultos e representantes do PB popular, enquanto as colocações comuns ao PE exibem maior percentual entre os escreventes comprovadamente cultos e cultos, por inferência identificados como "sem informação". Porém, é importante ressaltar a presença da inovação brasileira entre todos os níveis de escolaridade, o que aponta que, apesar da escolarização influenciar na frequência da colocação inovadora, todos os escreventes dos corpora utilizam uma colocação característica do PB na escrita.

\section{As vertentes se aproximam?}

De acordo com Lucchesi (1994), a história do PB favorece a polarização entre normas cultas, que estariam mais vulneráveis às influências 
oriundas da gramática do português europeu moderno devido à escolarização institucionalizada, enquanto que as normas vernáculas, por não sofrerem tanta pressão de uma norma padronizada baseada no português europeu, expressariam mais fortemente o PB. O autor coloca que tais normas tenderiam a se aproximar no decorrer do tempo como consequência dos processos de industrialização e urbanização ocorridos no Brasil durante o século XX.

Andrade e Carneiro (2014) buscam verificar se a hipótese de Lucchesi (1994) acerca da aproximação das normas pode ser verificada através da análise da colocação dos clíticos em complexos verbais em cartas datadas dos séculos XIX e XX, manuscritas pelo que eles chamam de escreventes cultos e incultos. Os autores afirmam, com base nos resultados obtidos, que

a separação dos dados em duas vertentes constituintes da sociohistória do PB não dá suporte à hipótese apresentada em Lucchesi (1994), e sim a uma abordagem mais próxima à que se defende em Tarallo (1993). Em suma, ambas as vertentes se distanciam da gramática do PE, sendo distintas somente quanto à rapidez com que ocorre a mudança. (ANDRADE E CARNEIRO, 2014, p. 155)

No entanto, os pesquisadores ressaltam que os resultados encontrados por eles não invalidam a hipótese de Lucchesi (1994), mas evidenciam que "a extensão de suas previsões é mais limitada do que ele previa originalmente" (ANDRADE E CARNEIRO, 2014, p. 155), visto que, para eles, Lucchesi (1994) estuda, de formal geral, fenômenos de naturezas distintas e, por este motivo, afirmam que os fenômenos sintáticos podem estar menos vulneráveis a variações em condicionantes externos.

Sobre a colocação dos clíticos, o que se pode perceber, nos resultados dessa pesquisa, é que há uma aproximação entre as vertentes aqui consideradas, na modalidade escrita, confirmando o que coloca Lucchesi (1994). Como é visto no contexto de sentença V1, a colocação majoritária é de ênclise em todas as vertentes, apresentando um padrão de colocação em desacordo com o PB. Estes resultados, entretanto, denotam uma maior pressão da norma 
padronizadora, adquirida entre escreventes cultos e semicultos nos processos de escolarização institucionalizada, mas também, exercem, em algum nível influência na colocação dos escreventes pouco ou não escolarizados.

Sobre contexto de variação $I$, a colocação pós-verbal é utilizada por escreventes de todas as vertentes, porém, seu percentual entre escreventes semicultos e pouco ou não escolarizados, é muito inferior aos resultados obtidos entre escreventes cultos. Além disso, os dados de hipercorreção, com uso da ênclise em contextos historicamente categóricos de próclise, também devem ser levados em consideração ao interpretar as colocações pós-verbais dos escreventes cultos neste contexto, visto que a hipercorreção evidencia a pouca propriedade desses escreventes cultos acerca de uma colocação dos clíticos conforme a norma padronizadora. Além disso, a colocação em próclise é vista de forma majoritária em todos os tipos de escreventes, o que também contribui para uma confirmação da aproximação entre as vertentes.

Nas construções com grupos verbais, a subida do clítico apresenta um menor percentual em relação à não subida, porém, ainda que a subida do clítico seja notada em maior número entre escreventes cultos, também se percebe esse tipo de colocação entre escreventes pouco ou não escolarizados, revelando indícios de aproximação entre essas vertentes. Deve-se ressaltar, também, que a posição de inovação brasileira se apresenta consideravelmente em todas as amostras representativas de distintas vertentes do PB nestes corpora, o que denota a presença do PB de maneira ampla em todos os tipos de escreventes dos corpora dessa pesquisa.

É importante ressaltar ainda que, ao observar os dados em corpora de linguagem escrita, deve-se considerar o caráter não natural dessa modalidade, visto que a escrita está mais vulnerável às influências da norma padronizadora e, como visto nos resultados, pode-se notar a presença dessa pressão, em maiores ou menores graus, entre todos os tipos de escreventes das cartas que constitui os corpora estudados. Vale ressaltar novamente que na pesquisa de Carneiro (2016) na modalidade oral, há a generalização da próclise em todos 
os contextos sintáticos de colocação dos clíticos em dados tanto de falantes cultos quanto de falantes pouco ou não escolarizados, o que reforça como a norma padronizadora pode influenciar nos resultados.

\section{Conclusão}

Como já dito, este estudo objetivou realizar a descrição da colocação dos clíticos em corpora do sertão baiano representativo de três vertentes do PB: culta, semiculta e popular, como aponta Lucchesi (2015), realizando o seguinte questionamento:

Ao observar os resultados, no que tange ao padrão de colocação dos clíticos em contextos sintáticos relevantes por distinguir o PE do PB, é possível perceber uma aproximação entre as vertentes culta, semiculta e popular do PB, como aponta Lucchesi (1994), nas amostras dos corpora do século XX escritos por indivíduos do sertão baiano?

A hipótese elaborada foi a de que as vertentes podem revelar padrões distintos de colocação entre os documentos representativos das normas cultas, semicultas e populares, visto que, devido ao fato de ocorrerem em corpora de linguagem escrita, em que o uso da língua se dá de forma monitorada, a norma padronizadora pode exercer maior influência entre os escreventes cultos e semicultos. Além disso, supôs-se também que nas amostras de norma popular os padrões de colocação do PB sejam mais evidentes, uma vez que os escreventes são adultos pouco ou não escolarizados em fases iniciais de aquisição da escrita.

Em sentenças com verbo único, no primeiro contexto observado (verbo em posição inicial) a ênclise se apresentou categórica entre escreventes comprovadamente cultos e classificados como cultos por inferência, ao passo que entre os semicultos e pouco ou não escolarizados, ainda que houvesse $33,3 \%$ de próclise nos documentos de semicultos e $38,1 \%$ nos documentos dos indivíduos pouco ou não escolarizados, a ênclise se mostrou majoritária em

Confluência. Rio de Janeiro: Liceu Literário Português, n. 61, p. 299-334, jul.-dez. 2021 
ambas as amostras. Nesse contexto sintático, então, a hipótese de Lucchesi (1994) acerca da aproximação das vertentes é confirmada, mas, confirma-se também a presença do PB entre os documentos de indivíduos semicultos e pouco ou não escolarizados, através dos dados de próclise.

No contexto de variação I (verbo antecedido por sujeito neutro, sintagma preposicional ou sintagma adverbial, com advérbios não atratores de próclise), foi notada a presença de variação entre indivíduos comprovadamente cultos, com ênclise majoritária $(55,6 \%)$ e entre os considerados cultos através de inferência, com próclise majoritária (53,2\%). Entre escreventes semicultos e pouco ou não escolarizados a próclise foi ampla, registrando $80 \%$ da colocação em amostras do PB semiculto e $95,7 \%$ nas amostras do PB popular. Assim, percebe-se que neste contexto as amostras de semicultos e pouco ou não escolarizados evidenciaram uma aproximação substancial, ao passo que os cultos revelaram um percentual considerável da ênclise.

Ao analisar estes resultados, entretanto, é importante levar em consideração que era esperado entre os escreventes com maiores graus de escolaridade, uma maior influência do uso da norma padronizadora adquirida via escolarização institucionalizada, que é baseada no PE. Porém, além de analisar o alto percentual de ênclise, deve-se levar em consideração o percentual também alto da próclise entre esses indivíduos, 44,4\% entre em documentos dos comprovadamente cultos e $53,2 \%$ dos considerados cultos por inferência) o que pode permitir a relação da frequência de ênclise às influências da norma padrão adquirida via escolarização institucionalizada.

Nas construções com grupos verbais, notou-se a colocação majoritária da colocação sem subida do clítico (75,5\%), evidenciando um resultado em consonância com o $\mathrm{PB}$, principalmente pelo fato de que dos 185 dados de não subida do clítico, 138 dados são da próclise ao segundo verbo, ou seja, da colocação inovadora do PB. Entre os dados de subida, percebeu-se maior percentual de elevação nos verbos auxiliares temporais e aspectuais, causativos e modais nos dados do Acervo Dantas Júnior, caracterizado por ser constituído de documentos de escreventes cultos e 
maioria dos documentos de cunho formal. Porém, dados de subida do clítico também foram encontrados entre escreventes pouco ou não escolarizados da zona rural. Além disso, a colocação de inovação brasileira foi percebida de modo amplo em todos os tipos de escreventes e documentos. Assim, é possível dizer que os resultados nas construções com grupos verbais revelam, assim como o contexto de verbo em posição inicial, a confirmação da hipótese de Lucchesi (1994).

Desse modo, considerando os resultados aqui explanados e os de Carneiro (2016), é possível perceber que a ideia de aproximação das vertentes mostradas por Lucchesi (1994) é viável e, inclusive, notável nas diferentes modalidades da língua nos corpora dessa pesquisa nos contextos de verbo em posição inicial, nas sentenças com verbo único, e no alto número não subida de clítico, evidenciando a próclise ao segundo verbo (colocação de inovação brasileira). Já no contexto de variação I, há uma aproximação substancial entre as vertentes semiculta e popular, porém um certo distanciamento da vertente culta, que apresenta uma variação relevante. Deve-se considerar, todavia, o caráter não natural da modalidade escrita que propicia um monitoramento da linguagem, bem como a possibilidade de influência da norma padronizadora, já que em amostras de fala espontânea de indivíduos cultos Carneiro (2016) evidenciou a total generalização da próclise.

\section{Referências}

ANDRADE, Aroldo Leal de. A subida de clíticos em português: um estudo sobre a variedade europeia dos séculos XVI a XX. Orientadora: Charlotte M. Chambelland Galves. 2010. 360 f. Tese (Doutorado em Linguística Histórica) - Instituto de Estudos da Linguagem, Universidade Estadual de Campinas, Campinas, 2010.

BORTONI-RICARDO, Stella Maris. Nós cheguemu na escola e agora? Sociolinguística e educação. São Paulo: Parábola, 2005. 
CARNEIRO, Zenaide. Cartas Brasileiras: um estudo linguístico-filológico. Orientadora: Charlotte M. Chambelland Galves. 2005. 2246 f. Tese (Doutorado em Linguística Histórica) - Instituto de Estudos da Linguagem, Universidade Estadual de Campinas, Campinas, 2005.

CARNEIRO, Zenaide. Colocação de clíticos em orações finitas em duas vertentes do português oral feirense: um contexto não variável. In: ALMEIDA, Norma Lucia Fernandes de; ARAÚJO, Silvana Silva de Farias; TEIXEIRA, Eliana Pitombo; CARNEIRO, Zenaide (orgs.). Variação linguística em Feira de Santana - Bahia. Feira de Santana: UEFS Editora, 2016.

CARNEIRO, Zenaide; OLIVEIRA, Mariana Fagundes; ALMEIDA, Norma Lúcia (orgs). Cartas brasileiras (1809 - 2000): coletânea de fontes para o estudo do português. Vol. 2 (1902 - 1993). Feira de Santana: UEFS Editora, 2011.

GALVES, Charlotte. A língua das caravelas: periodização do português europeu e origem do português brasileiro. In A. De Castilho; M.A. Torres Moraes; R. Vasconcellos Lopes, \& S. M. Lazzarini Cyrino (org). Descrição, História e Aquisição do Português Brasileiro. Campinas: Pontes, 2007, pp. 513-528.

GAlves, C., BRITTO H.; PAIXAO DE SOUZA, M. C. (2005 [2002, 2003]). The change in clitic placement from classical to modern european portuguese: results from the Tycho Brahe Corpus. UNICAMP.

GALVES, C.; RIBEIRO, I.; TORRES-MORAIS, M. A. Syntax and morphology in the placement of clitics. European and Brazilian Portuguese. Journal of Portuguese Linguistics 4:2, p. 143-177, 2005.

GALVES, Charlotte. Ensaios sobre as gramáticas do português. Campinas, São Paulo: Editora da Unicamp, 2001.

GALVES, Charlotte; CARNEIRO, Zenaide. Variação e Gramática: colocação de clíticos na história do português brasileiro. Revista de Estudos da Linguagem: UFMG, v.18-2, p.7-38, 2010. 
GALVES, Charlotte; PAIXÃO DE SOUSA, Maria Clara; NAMIUTI, Cristiane. Novas perspectivas para antigas questões: revisitando a periodização da língua portuguesa. In: ENDRUSCHAT, A.; KEMMLER, R.; SCHAFER-PRIEB, B. (Org.) Grammatische Strukturen des Europaischen Portugiesisch. Tubingen: Calepinus Verlag, 2006.

$\mathrm{KROCH}$, Anthony. Morphosyntactic Variation Proceedings of the 30th annual meeting of the Chicago Linguistics Society, vol 2, pp. 180-201, 1994. KROCH, Anthony. Syntactic Change. In Mark Baltin\& Chris Collins (orgs.), Handbook of Syntax, Blackwell, 2001.

LEMOS, Maiara. A colocação dos clíticos em sentenças finitas: um estudo sócio-histórico das vertentes do $\mathrm{PB}$ em cartas do sertão baiano (século XX). Dissertação de Mestrado. Feira de Santana: UEFS, 2019.

LOBO, T. C. F. Arquivos, acervos e a reconstrução histórica do português brasileiro. In: OLIVEIRA, K.; CUNHA E SOUZA, H. F.; SOLEDADE, J. (Orgs.). Do português arcaico ao português brasileiro: outras histórias. Salvador: EDUFBA, 2009.

LOBO, Tania. A colocação dos clíticos em português: duas sincronias em confronto. Orientadora: Rosa Virginia Mattos e Silva. 1992. Dissertação (Mestrado em Linguística Portuguesa Histórica) - Faculdade de Letras da Universidade de Lisboa, Lisboa, 1992

LUCCHESI, Dante. A deriva secular na formação do português brasileiro: uma visão crítica. IN: LOBO, T., CARNEIRO, Z., SOLEDADE, J., ALMEIDA, A., and RIBEIRO, S., orgs. Rosae: linguística histórica, história das línguas e outras histórias [online]. Salvador: EDUFBA, 2012, pp.249-274.

LUCCHESI, Dante. As duas grandes vertentes da história sociolingüística do Brasil. DELTA. São Paulo, n. 17, v. 1, 2001, p. 97-130.

LUCCHESI, Dante. Língua e sociedade partidas: a polarização sociolinguística do Brasil. São Paulo: Contexto, 2015. 
LUCCHESI, Dante. O conceito de transmissãolinguística irregular e o processo de formação do português do Brasil. In: RONCARATI, C; ABRAÇADO, J. (Org.). Português brasileiro: contato linguístico, heterogeneidade e história. Rio de Janeiro: 7 Letras, 2003. p. 272-284.

LUCCHESI, Dante. Variação e norma: elementos para uma caracterização sociolinguística do português do Brasil. Revista Internacional de Língua Portuguesa. 1994;12:17-28.

MARQUILHAS, Rita. A faculdade das letras: Leitura e escrita em Portugal no séc. XVII. Lisboa: Imprensa Nacional-Casa da Moeda, 2000.

MARTINS, Ana Maria. Clíticos na História do Português. Orientadores: Ivo Castro e Juan Uriagereka Tese de doutoramento. 1994. F. 332f. Tese (Doutoramento em Linguística Portuguesa). Faculdade de Letras da Universidade de Lisboa, Lisboa, 1994.

MARTINS, Ana Maria. A posição dos pronomes pessoais clíticos. In: Gramática do Português. Orgs RAPOSO, Eduardo Paiva; BACELAR, Maria Fernanda; MOTA, Maria Antónia; SEGURA, Luísa \& MENDES, Amália. Lisboa: Fundação Calouste Gulbenkian, 2013. p.2231-2302.

MARTINS, Marco Antonio. Sintaxe e padrões de variação: próclise e ordem SV no Português do Brasil. Linguistic Studies (Lisboa), v. 1, 2008, p. 161-178, 2008.

MARTINS, Marco Antônio. Competição de gramáticas do português na escrita catarinense dos séculos 19 e 20. Orientadoras: Izete Lehmkuhl Coelho e Maria Lobo. 2009. 326f. Tese (Doutorado em Linguística) Programa de pós-graduação em Linguística, Universidade Federal de Santa Catarina, Florianópolis, 2009.

MATTOS E SILVA, Rosa Virgínia. Caminhos da Linguística Histórica: ouvir o inaudível. São Paulo: Parábola Editorial, 2008. 
. Ensaios para uma sócio-história do português brasileiro. São Paulo: Parábola, 2004.

Virgínia. Para a história do português culto e popular brasileiro: sugestões para uma pauta de pesquisa. Caderno de Letras da UFF - Dossiê: Literatura, língua e identidade, no 34, p.11-30, 2008b.

PAGOTTO, Emílio. A posição dos clíticos em português: um estudo diacrônico. Orientadora: Charlotte M. Chambelland Galves. 1992. 179 f. Tese (Doutorado em Linguística Histórica) - Instituto de Estudos da Linguagem, Universidade Estadual de Campinas, Campinas, 1992.

PAGOTTO, Emílio; DUARTE, Maria Eugênia. Gênero e norma: avós e netos, classes e clíticos no final do século XIX. In: Lopes, Célia Regina dos Santos. (Org.). A Norma Brasileira em Construção: fatos linguísticos em cartas pessoais do século 19. 1a.ed. Rio de Janeiro: In-Fólio, 2005, v. p. 67-82.

SANKOFF, D. et al. Goldvarb X: a multivariate analysis application. Toronto: Department of Linguistics; Ottawa: Department of Mathematics. 2005. Disponível em: <http://individual.utoronto.ca/tagliamonte/Goldvarb/ GV_index.htm\#ref>. Acesso em: 24 de novembro de 2017.

SANTIAGO, Huda da Silva. A escrita por "mãos inábeis": uma proposta de caracterização. Orientadores: Zenaide de Oliveira Novais Carneiro e Afrânio Gonçalves Brabosa. Tese (Doutorado - Língua e Cultura) Programa de Pós-Graduação em Língua e Cultura, Universidade Federal da Bahia, Salvador, 2019.

TORRES MORAIS, Maria Aparecida. Mudança na colocação dos clíticos na história do português. Boletim da ABRALIN. 1995; 17:32-40. 